Review article

\title{
The effectivity role of community mental health worker for rehabilitation of mental health illness: A systematic review
}

\author{
Liana Liana $^{\text {a }}$, Heni Dwi Windarwati ${ }^{\text {a, } *, 1}$ \\ ${ }^{\text {a }}$ Nursing Department, Faculty of Medicine, Universitas Brawijaya, Malang, Indonesia
}

\section{A R T I C L E I N F O}

\section{Keywords:}

Community mental health worker

Mental illness

Rehabilitation

\begin{abstract}
A B S T R A C T
Background: The effectivity role of community mental health worker (CMHWs) has several important gaps in the service provision at the community level. This study aimed to explain community mental health workers' effectivity role for the rehabilitation of mental health illness.

Methods: A systematic review searched five electronic databases (Scopus, PubMed, ScienceDirect, CINAHL, and ProQuest) for previous studies published between 2015 and 2020. The Centre for Review and Dissemination and the Joanna Briggs Institute Guideline used to assess quality and Prisma checklist guided this review. Title, abstract, full-text and methodology were assessed for the eligibility of the studies. Data tabulation and narrative analysis of study findings were performed.

Results: We found 10 studies which discuss the role of community health worker and the effectivity were community health workers as a primary care giver, counselor, partner for mental health patient, the effectiveness also produce government policy in community health worker existence, and improving self-advocacy and patient outcomes.

Conclusion: The role of CMHWs in mental health is to become caregiver, partner, support, efficacy and improve the patients' condition. Based on the finding, the suggestion was the part of CMHWs becomes important to increase the health condition of mental patients during rehabilitation.
\end{abstract}

\section{Introduction}

Mental, neurological, and substance use disorders contribute significantly to the global burden of disease, ac-counting for $21.2 \%$ of years lived with disability. ${ }^{1}$ The limited number of professional mental health staff creates a critical gap in providing accessible treatment for people with mental illness. ${ }^{2}$ Community health workers are indigenous members of patients' communities who have been trained to provide support, $^{3,4}$ education, ${ }^{5,6}$ and care coordination ${ }^{7}$ to improve medical outcomes for low-income and at-risk populations. ${ }^{8}$ The scarcity of mental health professionals, in particular, places specialized psychiatric care out of reach of most people in low- and middle-income countries (LAMICs), especially in the lowest income countries and in rural/low-income regions within countries. ${ }^{9}$ In a study of 58 LAMICs, Bruckner et al. ${ }^{10}$ reported that the mental health workforce's shortage amounts to about 239,000 workers, including 11,000 psychiatrists, 128 , 000 nurses in mental health settings, and 100,000 psychosocial care providers. The WHO estimates that 1.18 million additional mental health workers are needed to close the mental health treatment gap in LAMICs. $^{11}$

Increasingly, community health workers are being used to provide transitional care interventions to patients who are deemed to be at risk of unplanned readmission following discharge from a medical hospitalization. ${ }^{12-14}$ Once patients have returned home, community health workers provide care coordination and patient navigation to promote greater access to care and integration of complex services required by many health conditions. ${ }^{15,16}$ These services are designed to ensure the safe and timely movement of patients from the hospital to their homes while preventing avoidable readmissions and ensuring that positive health outcomes can be sustained. ${ }^{17}$

The effectivity role of community mental health worker (CMHWs) have several important gaps in the service provision at the community level within mental health delivery system ${ }^{18}$; however, the most of CMHWs surveyed expressed confidence in their ability to recognize and treat most of the common mental disorders, ${ }^{7,19}$ but only about a quarter of all CMHWs work closely with psychiatrists, psychologists, and social

\footnotetext{
* Corresponding author. Department of Mental Health Nursing, Faculty of Medicine, Universitas Brawijaya, 64145, Malang, Indonesia.

E-mail address: henipsik.fk@ub.ac.id (H.D. Windarwati).

1 Postal address: Veteran Street, Malang, East Java Indonesia.
} 
workers, and a similar proportion collaborate with traditional healers. ${ }^{20}$

Many factors influence the effectivity role of CMHWs in a community ${ }^{21}$; the result of a previous study in Ghana showed these including the prospects of easy employment, ${ }^{22,23}$ stigma, ${ }^{24}$ risk and lack of opportunities for career progression and low salaries. ${ }^{25}$ A study conducted in India also stated that considering the disparity between population and the demand for mental health care, interventions through the community could be a viable option. ${ }^{26,27}$ Most of the research focuses on the quantitative study about the effectivity role of CMHWs. ${ }^{20}$ However, there are still limited research articles that explore the effectivity role of CMHWs base on qualitative studies. This review study aimed to identify community mental health workers' effectivity role for rehabilitation of mental health illness in community.

\section{Methods}

A systematic review was conducted as a comprehensive and synthesis of relevant studies about community mental health workers' effectivity role for rehabilitation of mental health illness in community. The Centre for Review and Dissemination and the Joanna Briggs Institute Guideline ${ }^{28,29}$ guided the assessment of study quality. The systematic review evaluation was performed using the PRISMA checklist of items to include while reporting and analysing a systematic review. ${ }^{30}$

\section{Search strategy}

Scopus, PubMed, ScienceDirect, CINAHL, and ProQuest were electronic databases used to search relevant studies, and databases search was conducted from August 2020 to identify relevant studies. The PICOS question $(\mathrm{P}=$ population, $\mathrm{I}=$ intervention, $\mathrm{C}=$ comparators, $\mathrm{O}=$ outcomes, $\mathrm{S}=$ study type) format was used for formulating the research question (Table 1). The boundaries of the review question were defined through the development of inclusion and exclusion criteria using the PICOS format. Studies were included for review if they met the following inclusion criteria ${ }^{1}$ : All types of qualitative study whether mixed methods (qualitative and quantitative study) and only qualitative research conducted in $\mathrm{CMHWs}^{2}$; Outcomes related to the effectivity role of CMHWs (see Table 2).

Strategies for each database search were enhanced after trying and consulting with a specialist in systematic review strategies. The literature search was performed with four groups of keywords based on Medical Subject Heading (MeSH) ${ }^{31,32}$ and combined with Boolean operators AND, OR, and NOT. The search strategy was established as: ("effectivity role" OR function OR duties") AND (community mental health worker* OR community health worker OR "health volunteer" OR "cadre") AND (Rehabilitation OR Community Mental Health Nursing) AND ("Mental Health Illness" OR "Mental Health Diseases" OR Mental

Table 1

The PICOS format.

\begin{tabular}{|c|c|c|}
\hline Criteria & Inclusion & Exclusion \\
\hline Population & $\begin{array}{l}\text { Community Mental Health } \\
\text { Worker }\end{array}$ & Profesional worker \\
\hline Issue of Interest & $\begin{array}{l}\text { role of community mental } \\
\text { health worker }\end{array}$ & $\begin{array}{l}\text { Non- role of community } \\
\text { mental health worker }\end{array}$ \\
\hline Comparators & No comparator & \\
\hline Outcomes & $\begin{array}{l}\text { the effectivity role of } \\
\text { community mental health } \\
\text { worker for the rehabilitation } \\
\text { of mental health illness in the } \\
\text { community }\end{array}$ & $\begin{array}{l}\text { Not described the effectivity } \\
\text { role of community mental } \\
\text { health worker for the } \\
\text { rehabilitation of mental } \\
\text { health illness in the } \\
\text { community }\end{array}$ \\
\hline $\begin{array}{l}\text { Study Design and } \\
\text { publication } \\
\text { type }\end{array}$ & $\begin{array}{l}\text { qualitative research and mix } \\
\text { methods }\end{array}$ & Quantitative research \\
\hline Publication years & Post-2015 & Pre-2015 \\
\hline Language & English & Language other than English \\
\hline
\end{tabular}

Health Disorder). The search results were limited to qualitative studies published in either Indonesian or English language during 2015-2020. The time limit was set because researchers needed the most recent studies to develop theoretical models and prepare for conduct current studies in nursing and health.

\section{Study selection}

Two hundred and fifty-nine publications were found from the database searches (Fig. 1), publications duplicated $(n=51)$ were removed from the results, leaving a total of 208 records. Researchers assessed and screened the title $(n=208)$, abstract $(n=52)$ and full text $(n=10)$ of each publication irrelevant of inclusion criteria (Table 1). We found eleven full-text articles were eligible to conduct a systematic review. Researchers defined common reasons for exclusion criteria during the literature screening process, including irrelevant study type, no complete explanation of the factors that influence psychological disturbance or stigma, and grey literature.

\section{Assessment of study quality and risk of bias}

The JBI Critical Appraisal for Qualitative Studies was used to assess the methodology's quality in each study $(n=10)$. The checklist for studies suitable had various assessment criteria. Criterion assessment was given a score of 'yes', 'no', 'unclear' or 'not applicable'. Every criterion with score 'yes' was given one point and, following this, each study score was calculated. Researchers performed critical appraisal to assess the eligible studies. ${ }^{33,34}$ If the score of the study was at least $50 \%$ during the critical appraisal, which was the predetermined cut-off point agreed by both researchers, studies were included in the review. Researchers excluded low-quality studies to avoid compromising the validity of the results and recommendations of the review. ${ }^{30}$ In the last screening, eighteen studies reached a score higher than $50 \%$ and were ready to do data synthesis. Unfortunately, due to the risk of bias assessment, seven studies were excluded.

\section{Data extraction and analysis}

The relevant data the review question was extracted, including author, country, year, setting, theoretical framework, research aim, the conceptualization of cultural competence, educational content, study design, sample size, sampling method, description of participants, reliability, and validity, measurement instruments, analysis and statistical techniques, outcomes related to cultural competence, and the analysis of the results. A narrative approach with the primary goal to aggregate evidence on the effectiveness of the interventions and develop a coherent textual narrative on commonalities and differences between studies was used to synthesize the data in this systematic review.

\section{Results}

Total articles collected were 10 articles. After reviewing the following results, there were 7 articles were qualitative research design and 3 other articles were quasi-experimental, cross-sectional, and mixed methods. This Systematic review discusses the effectiveness of CMHWs role during rehabilitation in mental illness. Three articles discussed Community health workers as a primary care giver, one article discussed about government, two articles explain as listener, five articles found as a partner and support and two articles found that the role of CMHWs can improving patient self-advocacy and better outcomes.

\section{Study characteristics}

Ten articles met the inclusion criteria (Fig. 1). Included studies fall into broad thematic areas. There were factors affecting community health worker intervention, community health workers as a primary 
Table 2

Article analysis.

\begin{tabular}{clll}
\hline Authors and years & Study design & Participant & Instrument/Intervention \\
\hline (Surjaningrum, & Qualitative design & 62 participants from four groups of & characteristics and \\
2018) & & stakeholders in primary healthcare in & competencies required by \\
& Indonesia & CHWs to identify and refer \\
& & perinatal depression.
\end{tabular}

(Agyapong, Farren \& Qualitative design McAullife, 2016)

(Myers et al., 2018) Qualitative design

(Agyapong et al.,

Cross sectional 2015)

(Reed, Josephsson \& Qualitative design Alsaker, 2017)
11 psychiatrists and 29 health policy directors in Ghana

Forty chronic disease patients (20 with HIV, 20 with diabetes) reporting hazardous alcohol use or depression, interview with 7 CMHW in Africa

11 psychiatrists, 29 health policy directors and 164 CMHWs across Ghana

Seven community mental health worker in Sweden

Summary of Results

The study describes information on the role of community health workers and the competencies needed to identify and refer to perinatal depression. Many of the studies examining the role of CHW in mental health have not been based on a community environment, although there is general agreement that CHWs are selected and based on criteria established by the communities they serve. This study fills a gap in knowledge and provides the rationale for the recruitment criteria of CHW [29] in the specific context of maternal mental health care in Surabaya, Indonesia. The study findings show consistency with the criteria used in selecting CHW in many studies, and with guidelines for recruiting $\mathrm{CHW}$ in general and CHW in mental health in particular. Elements such as knowledge and skills are also consistent with those contained in the international guidelines for informal workers working in mental health issues published by WHO. Thus, a generalization of these findings to the management of CHW that plays a role in the identification of perinatal depression in other contexts can be made.

Government policy in Community Mental Health Worker Role for Mental Health

Three sessions of structured mental health counselling.

Factors contributing in CMHW intervention as a role in education community community mental health support
CMHW is given the responsibility of monitoring patients directly in the community, CMHW should be allowed to assess, diagnose, and treat the most common mental disorders. Government policy for the independence of CMHW in treating general mental health conditions. A comprehensive training curriculum is necessary to evaluate the work of all CMHWs in Ghana to ensure that they are consistent with the health care demands and needs of the patients they care for in their community. The role of CMHW can also help health workers to monitor patients and take immediate action if something dangerous and emergency occurs.

The results showed that a large proportion of the public indicated that they agreed with the existence and eligibility of CHW to be acceptable using either a specific or designed approach to mental health counselling that $\mathrm{CHW}$ provided, some modifications to recruitment, CHW training and implementation counselling protocols could increase the likelihood of successful implementation. We have adapted this protocol that is now used in cluster randomized controlled trials comparing the clinical effectiveness and costs of specific and designated approaches to mental health counselling that $\mathrm{CHW}$ provides to improve mental and chronic health.

Factors that can influence the provision of intervention and the role of CMHW are easy job prospects, stigma, risk, lack of opportunities for career advancement and low salaries. Selection of CMHW really needs to be selected to ensure their motivation to want to train as CMHW before they are enrolled in the program, so the intervention given is very good. The Ministry of Health of Ghana and the Mental Health Authority of Ghana also need to comprehensively address the factors that have the potential to dampen the enthusiasm of these health cadres by expanding the ministry's existing underdeveloped area incentive schemes to provide improved security and logistics as well as clear salary and career path increases for CMHW.

Community mental health workers providing support to patients need support from all systems so that they can provide good benefits to patients with mental health disorders. Negotiation involves new roles and a complex collaborative process, in which user, professional, and systemic

(continued on next page) 
Table 2 (continued)

\begin{tabular}{clll}
\hline Authors and years & Study design & Participant & Instrument/Intervention \\
\hline & & & \\
& & & \\
(Tilahun et al., & $\begin{array}{l}\text { A quasi experimental } \\
\text { research design with } \\
\text { pre and post assessment }\end{array}$ & 27 participant every groups in India & $\begin{array}{l}\text { Community mental health } \\
\text { worker for elderly }\end{array}$
\end{tabular}

(Michael et al., 2018)

Qualitative study design
South Australian community mental health patients $(\mathrm{n}=8)$ and mental health workers $(n=10)$
8 patients on CTOs and 10 community mental health workers in South Australia
Community mental health worker and moral framing
Community mental health worker with metaphors methods
The role CMHW and group support
Summary of Results

perspectives are considered and negotiated in any given situation. By engaging in negotiations, professionals can provide appropriate support with recommendations for collaborative services. The increasing number of elderly people in the country in recent years shows the need for strategies to tackle growing mental health problems. Given the disparity between the population and the need for mental health care, community intervention may be a viable option. Community-led interventions will inevitably reduce inequalities in health care. Strengthening primary care systems is more relevant in the current scenario and governments must take action to support them in service delivery. Training CHW in identifying and teaching strategies to prevent mental illness in the elderly can facilitate timely interventions in the community as well as cost effective methods for developing countries like India.

The moral framework is seen in participants' construction and evaluation of CMHW experiences as positive, negative, or justifiable. CMHW uses a moral framework to justify the application of care and provide empathy, as well as positive rights of patients to care and treatment, which they believe will only happen to patients. Workers position themselves in an attempt to put themselves in the patient's shoes as a way of acting well with them, softening the coercive stick approach. Four themes were identified: explicit moral framing; the best interest of the patient; lessons learned by patients; and, empathy. The CMHW experience has many layers, and relies heavily on empathy and reflection on the relationship between what is done and how it is done. This includes an explicit examination of the moral framing that exists in the daily interactions between mental health workers and their patients to overcome the moral grey zone paradox between caring and controlling. This demonstrates the need for workers to receive ongoing empathy training.

Metaphors are the way mental health patients and mental health workers articulate the nature of CMHW. The language used to construct this metaphor is very different, with highly experienced patients perceiving CMHW as coercive (i.e., punishing, controlling, and researching), whereas workers tend to find it necessary, useful, and supportive, regardless of their compulsion. By recognizing the role of metaphors in these patients' lives, workers can increase the chances of engaging these patients in more meaningful dialogue about their personal experiences as an alternative to practices that are primarily risk-focused. Such dialogue can enhance workers' reflection on their work and promote recovery-based practices. More understanding of how to promote autonomy, supported capacity and decision-making, and how to deal with the impact of collaborative care on care, is needed. This study underscores the need for a creative approach to rural depression treatment that draws on community-based skills and human resources. We must rethink depression treatments for rural women, whose ability to recognize their depression and seek treatment for it is challenged by high rates of physical comorbidity, extended family responsibilities, and gender-based power expectations. In the absence of sufficient rural health care professionals to meet the broad needs of rural areas, CHWs can recognize silent and articulated mental health needs; provide culturally appropriate and reliable support to 
Table 2 (continued)

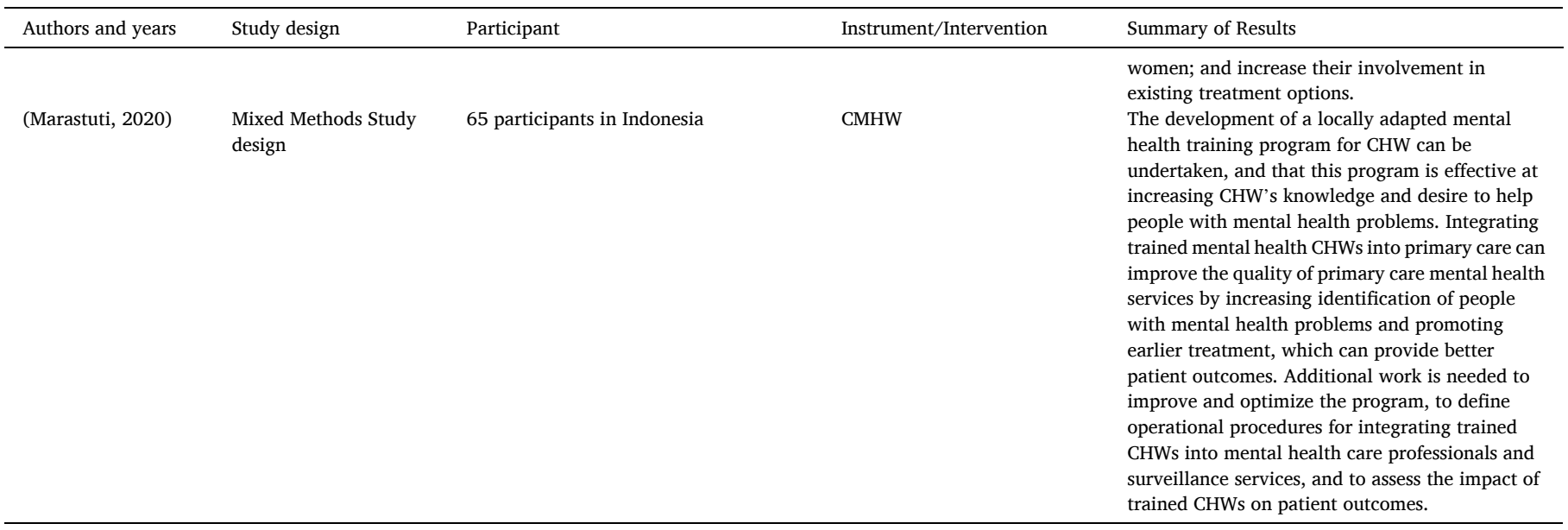

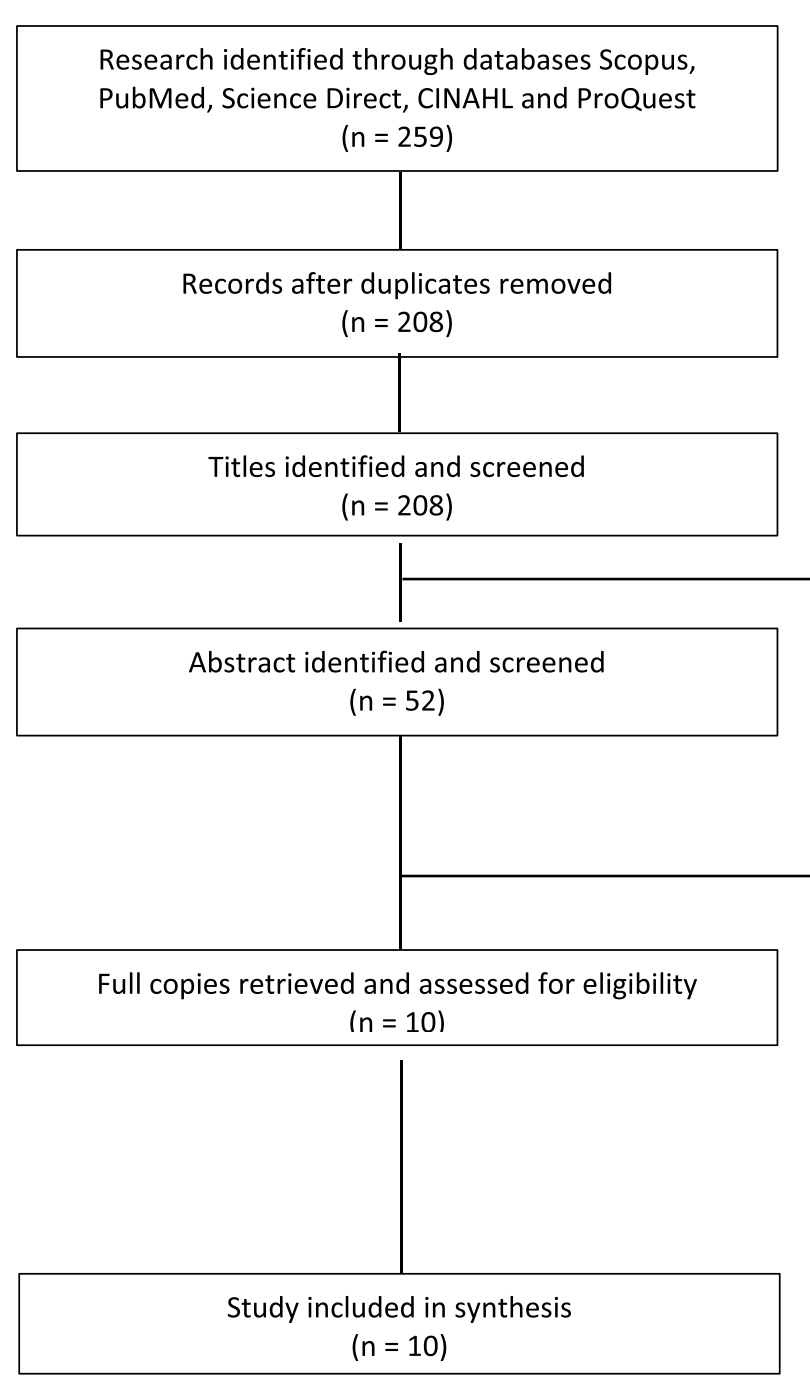

Fig. 1. Flow chart of literature review adopted from PRISMA 2009 Flow Diagram.

caregiver, counselor, partner, government policy in community health worker existence, and improving self-advocacy and patients outcomes. The CMHW roles are mostly qualitative research, quasi-experimental, and cross-sectional. The median number of participants is more than one hundred; overall, every study discussed the role of CHW and the impact of CHW intervention. The studies appropriate with this systematic review were average conducted in Indonesia, Africa, America, and Ghana.

Community health workers as a primary caregiver

The role of CHW is significant in primary health care because they 
will directly contribute and provide first-line care to patients. One study conducted on participants with perinatal depression showed a very maximal role for CHW in treating mental health problems. They give caring for and facilitating the client to improve satisfaction. CHW can provide comfort and reduce participant depression through education and optimal psychological intervention. The knowledge that $\mathrm{CHW}$ has acquired every time they train enables them to provide appropriate education to participants regarding pregnancy, maternal life, child development, perinatal depression, communication techniques, and specific knowledge, such as how to change attitudes and risk factors. Good understanding of perinatal mothers can reduce anxiety and prevent depression from recurring. CHW's ability to communicate and build trusting relationships with participants also makes it comfortable so that participants will be more open in telling the problems they are facing. When participants tell and believe in CHW, the problems they face can think of solutions simultaneously, and participants can also get counselling from the opinions expressed by CHW.

The increasing number of older people in the country in recent years shows the need for strategies to tackle growing mental health problems. Given the disparity between the population and the need for mental health care, community intervention may be a viable option. Community-led interventions will inevitably reduce inequalities in health care. Strengthening primary care systems is more relevant in the current scenario, and governments must support them in service delivery. Training CHW in identifying and teaching strategies to prevent mental illness in the elderly can facilitate timely interventions in the community and cost-effective methods for developing countries like India. $^{11}$

\section{Government policy in community health worker existence}

The majority of respondents, namely psychiatrists and health policy directors, believe that CMHW is an important element in the community and must be maintained. CMHW is given the responsibility of monitoring patients directly in the community. CMHW should help healthcare workers give data to assess, diagnose, and treat the most common mental disorders. Respondents identified that CMHW usually performs two sets of roles, namely, formally defined roles for which they have the necessary training and assumed roles for which they usually do not have the required training. Stakeholders identified various challenges associated with current task-shifting arrangements in the Ghanaian mental health delivery system, including inadequate training and supervision, poor awareness of the scope of their expertise on the part of CMHW. This study highlights several important reasons for task shifting and gaps in service delivery at the community level in the mental health delivery system in Ghana. The study also determined that many psychiatrists and health policy directors in Ghana supported the Government's policy of self-reliance on CMHW in treating common mental health conditions. The overall training curriculum is necessary to evaluate the work of all CMHWs in Ghana to ensure that they are consistent with the health care demands and needs of the patients they care for in their community. The role of CMHW can also help health workers to monitor patients and take immediate action if something dangerous and an emergency occurs.

\section{Community health workers as a listener}

The existence of Community Mental Health in providing services to patients shows good results in mental health. The qualitative research was undertaken described CHWs' perceived confidence in their ability to be a listener, the proposed counselling package and CHW's experiences about barriers to delivery of suggestion and their recommendations for reducing this resistance. All CHWs view the intervention as acceptable and beneficial for patients with chronic disease. The patient is very satisfied with the service provided by CHW, "It seems that when I did the first session, they cannot wait for the second session to give me input". All CHWs can provide concrete examples of how patients apply the problem-solving skills they have learned to solve problems.

According to CHWs, support from primary healthcare facilities, other CHWs, and their employing NGOs (if any) is essential to facilitate the delivery of counselling. In facilities where the designated and dedicated CHW described facility staff as 'supportive' and 'interested', counselling went smoothly.

CHW feels more empowered to provide intervention to patients in meeting their counselling needs. The realignment of the CHW team's responsibilities to accommodate mental health counselling took place organically in some (but not all) of the designated locations. To facilitate this alignment in the future, the appointed CHW felt it would help employers and NGO supervisors be more involved in training and discussions on implementing interventions. ${ }^{35}$

\section{Community as a partner and support}

Like other rural communities, mental hospitals, community mental health care centres are located in big cities, so rural areas need first-rate health facilities. However, patients have difficulty accessing care due to transportation constraints, long waiting lists in community mental health centres, and poverty. Throughout, participants emphasized the benefits of having CHW play a deeper role in engaging women with depression in treatment and improvement.

Some participants warned that support groups for depression in Appalachia needed to avoid prescriptive self-care lessons. The focus should be on social support rather than mental health alone. Noting widespread concerns about social anxiety and a loss of confidentiality in rural communities, CHW warned that rural women would be more receptive to group sessions if $\mathrm{CHW}$ met with them individually before group meetings. Such a visit would prepare women for peer support options before attending a group session so that they would anticipate "'There is another person who feels what I am doing and has the same problem' and it might ease the door open for someone." Through CHW's role in creating new social relationships and facilitating peer group support, participants imagined that $\mathrm{CHW}$ would reduce the isolation of rural women by de-individualizing their struggles and "letting [ting] them know that they are not the only ones in the community. That struggle. "

Some have suggested that CHWs would be ideal facilitators for manual group interventions that do not require further education, such as Health Recovery Action Planning, as they would not use the specific mental health language that might come. More natural for someone with advanced training in behavioural health.

\section{Improving patient self-advocacy in primary care}

Although primary care is the primary setting for the treatment of rural depression, CHW recognizes that many opportunities to provide treatment are missed in this setting. They found that, "many people were close to tears and they did not know why they felt that way", yet many still "did not mention anything to their family doctors and to many people who were the only people they saw." Because patients often had doubts. Hesitant to assert their mental health needs, CHW advises the importance of counselling. CHWs are accustomed to mediating hierarchical relationships between patients and providers that many patients feel uncomfortable. Service providers recognize that CHWs refer their clients to them, work with clients for further medication adherence, and remove barriers to attending appointments.

Improving Pharmacotherapy Adherence With many patients juggling multiple drugs for their comorbidities, participants suggested that CHW plays an essential role in explaining the purpose and use of depression medication. Service providers hope that further $\mathrm{CHW}$ training will enable them to offer primary education on treatment to prevent the demand for certain types of treatment that may pose a higher risk. 


\section{Improving better patients' outcomes}

The development of a locally adapted mental health training program for CHW can be undertaken, and that this program is effective at increasing CHW's knowledge and desire to help people with mental health problems. Integrating trained mental health CHWs into primary care can improve the quality of primary care mental health services by increasing identification of people with mental health problems and promoting earlier treatment, which can provide better patient outcomes. Additional work is needed to improve and optimize the program, to define operational procedures for integrating trained CHWs into mental health care professionals and surveillance services, and to assess the impact of trained CHWs on patient outcomes.

\section{Discussion}

The role of CMHW has been critical to mental health crises in providing interventions to patients. Community mental health has been introduced in various regions, Indonesia, which is commonly referred to as a health care. ${ }^{36,37}$ The role of CMH in helping health workers is very many. The training provided determines the ability of $\mathrm{CMH}$ during activities to provide education or treatment to the community. ${ }^{38}$ Disturbed mental health conditions, including chronic diseases that must be considered comprehensively. ${ }^{39,40}$ Several factors influence the role of CMHW influence the role of CMHW influence the role of CMHW influence the role of CMHW influence the role of CMHW, so it also affects the success rate of therapy. ${ }^{41,42}$ The influencing factor is the motivation of every CMHW in Ghana to join as a mental health care. ${ }^{7,13}$ The level of knowledge and training that has been carried out by CMHW also has a major effect on CMHW's ability to provide interventions to people with mental health disorders. This is in accordance with a study that states that a person's readiness to face an event is influenced by his/her abilities and motivation in him. Individuals in carrying out roles become more confident.

The maximum role of $\mathrm{CHW}$ in providing caring and overcoming mental health problems is able to provide comfort and reduce participant depression through education and optimal psychological intervention. ${ }^{43,44} \mathrm{CHW}$ will increase public knowledge, due to its position as the first level engaged in the promotion and prevention of health problems. $^{6,22}$ Education that is right on target and needed by the community can increase the community's knowledge and information so that patients can finish faster.

One of the studies that has been analysed shows that the importance of education and counselling in the community plays a big role in increasing patients' resilience and coping mechanisms during mental health disorders. ${ }^{45}$ One study shows mental health problems during pregnancy. If intervention is not given immediately, the risk of making the mother become depressed and fall into chronic mental disorders. ${ }^{19}$ CHW's role is to provide education and counselling to mothers regarding maternal life, child development, perinatal depression, communication techniques, and specific knowledge, such as how to change attitudes and risk factors. ${ }^{15}$ Good knowledge of perinatal mothers can reduce anxiety and prevent depression from recurring. CHW's ability to communicate and build trusting relationships with participants also makes it comfortable so that participants will be more open in telling the problems they are facing. When participants tell and believe in CHW, the difficulties they face can think of solutions simultaneously, and participants can also get counselling from the opinions expressed by CHW. ${ }^{46,47}$ This is following the working principle of psychoneuroimmunology in the body when the stress mechanism begins to be repaired.

Most of the community health centres are located in large urban centres, in people who have difficulty accessing them will cause treatment to be hampered. The participation of $\mathrm{CHW}$ has a high contribution to play a more profound role in involving the community in dealing with this condition. ${ }^{7,14}$ One example is Visiting women for peer support options before attending a group session so that they will anticipate "there are other people who feel what I do and have the same problem' and that might ease the door open for someone. There is a group that always provides a support system for them through the role of CHW in creating new social relationships and facilitating peer group support. ${ }^{19,48}$ Some have suggested that $\mathrm{CHW}$ would be ideal facilitators for manual group interventions that do not require further education, such as Action Planning Health recovery because they will not use the specific mental health language that might come more naturally to someone with advanced training in behavioural health.

\section{Conclusion}

The role of community health workers in mental health rehabilitation can act as primary caregiver, resulting in government policy, ccounsellor, community as a partner and support, improving patient self, advocacy, improvement, and improving patients' outcomes. The findings from this review can be used as a guideline for CMHWs in providing care for mental disorders patients after being discharged from the hospital and being treated in the community.

\section{Funding}

The author(s) received no financial support for the research, authorship, and/or publication of this article.

\section{Authorship}

Based on this systematic review, all authors have contribution to present the idea, searched some articles in the databases, analyse the article and conducted review manuscript. Liana wrote and revised the manuscript with support from all authors. Heni Dwi Windarwati give correction and consultation the manuscript, also all authors discussed the results and contributed to the final manuscript.

\section{Declaration of competing interest}

The authors declare, there is no conflict of interest of this study.

\section{Acknowledgement}

The authors express sincere gratitude to Nursing Department, Faculty of Medicine, Universitas Brawijaya, Malang. Also, we give thanks to all committee of the 1st International Nursing and Health Sciences Symposium and all participants that follow to conduct this study.

\section{References}

1 Sibeko G, Milligan PD, Roelofse M, et al. Piloting a Mental Health Training Programme for Community Health Workers in South Africa: An Exploration of Changes in Knowledge. 2018:1-10. confidence and attitudes.

2 Marastuti A, Sofia MAS, Carla R, Courtney RM, Byron MY, Good MJD. Development and evaluation of a mental health training program for community health workers in Indonesia. Community Ment Health J; 2020.

3 Liu A, Sullivan S, Khan M, Sachs S, Singh P. Community health workers in global health: scale and scalability. Mt Sinai J Med. 2011;78:419-435.

4 World Health Organization (WHO). WHO Guideline on Health Policy and System Support to Optimize Community Health Worker Selected Highlights [Internet]. WHO Guideline on Health Policy and System Support to Optimize Community Health Worker Selected Highlights. 2012. Available from:, https://apps.who.int/iris/bitstream/han dle/10665/275501/WHO-HIS-HWF-CHW-2018.1-eng.pdf?ua=1.

5 Olaniran A, Smith H, Unkels R, Bar-Zeev S, van den Broek N. Who is a community health worker? - a systematic review of definitions10. Global Health Action; 2017.

6 McCollum R, Gomez W, Theobald S, Taegtmeyer M. How equitable are community health worker programmes and which programme features influence equity of community health worker services? A systematic review16. BMC Public Health; 2016.

7 Spencer MS, Rosland AM, Kieffer EC, et al. Effectiveness of a community health worker intervention among African American and Latino adults with type 2 diabetes: a randomized controlled trial. Am J Publ Health. 2011;101:2253-2260.

8 Cook JA, Mueser KT. Community health Workers : potential allies for the field of psychiatric Rehabilitation?. 2015;38:207-209. 
9 Saraceno B, van Ommeren M, Batniji R, Cohen A, Gureje O, Mahoney J. Barriers to improvement of mental health services in low-income and middle-income countries. Lancet. 2007;370:74.

10 Bruckner T, Scheffler R, Shen G, Yoon J, Chisholm D, Morris J. The mental health workforce gap in low- and middle-income countries: a needs-based approach. Bull World Health Organ. 2011;89:94.

11 Fulton B, Scheffler R, Sparkes S, Auh E, Vujicic M, Soucat A. Health workforce skill mix and task shifting in low income countries: a review of recent evidence. Hum Resour Health. 2011;9.

12 Musoke D, Boynton P, Butler C, Musoke MB. Health seeking behaviour and challenges in utilising health facilities in Wakiso district, Uganda. Afr Health Sci. 2014;14:1046-1055

13 Hartzler AL, Tuzzio L, Hsu C, Wagner EH. Roles and functions of community health workers in primary care. Ann Fam Med. 2018;16:240-245.

14 Ludwick T, Brenner JL, Kyomuhangi T, Wotton KA, Kabakyenga JK. Poor retention does not have to be the rule: retention of volunteer community health workers in Uganda. Health Pol Plann. 2014;29:388-395.

15 Scott K, Beckham SW, Gross M, et al. What do we know about community-based health worker programs?. In: A Systematic Review of Existing Reviews on Community Health Workers. vol. 16. 2018. Human Resources for Health.

16 Blanks SH, Treadwell H, Bazzell A, et al. Community engaged lifestyle modification research: engaging diabetic and prediabetic african American women in communitybased interventions. J Obes. 2016;2016.

17 Bray-Hall ST. Transitional care: focusing on patient-centered outcomes and simplicity. Ann Intern Med. 2012;157:448-449.

18 Fikriana R, Nursalam N, Devy SR, Ahsan A, Afik A. The effect of coping strategies on the dietary regulation of patients with hypertension. Int J Psychosoc Rehabil. 2020;24: 7781-7787.

19 van Ginneken N, Tharyan P, Lewin S, et al. Non-specialist health worker interventions for the care of mental, neurological and substance-abuse disorders in low- and middle-income countries. 2013;2013. Cochrane Database of Systematic Reviews.

20 Agyapong VIO, Osei A, Farren CK, Mcauliffe E. Task Shifting - Ghana's Community Mental Health Workers' Experiences and Perceptions of Their Roles and Scope of Practice. 2015:9716.

21 Serrano Cardona L, Muñoz Mata E. Paraninfo Digital. Early Hum Dev [Internet]. vol. 83. 2013:1-11. Available from: https://www.sciencedirect.com/science/article/pii/ S0378378215300347?via\%3Dihub https://www.sciencedirect.com/science/article/ pii/S0378378214000036?via\%3Dihub https://www.sciencedirect.com/science/ article/pii/S0378378212700063?via\%3Dihub http://www.sciencedirect.com/sci ence/article/pii/S2341287914000763.

22 Jorm AF. Mental health literacy; empowering the community to take action for better mental health. Am Psychol. 2012;67:231-243.

23 President's New Freedom Commission on Mental Health. Achieving the Promise: Transforming Mental Health Care in America. Mental Health Care; 2003.

24 Nursalam N, Sukartini T, Priyantini D, Mafula D, Efendi F, Airlangga U. Risk factors for psychological impact and social stigma among people facing COVID-19. A. 2020; 11:1-6.

25 Agyapong VIO, Osei A, Farren CK, Mcauliffe E. Factors influencing the career choice and retention of community mental health workers in Ghana. Hum Resour Health. 2015;13:1-11.

26 Vinet L, Zhedanov A. A "missing" family of classical orthogonal polynomials. J Phys Math Theor. 2011;44.

27 Kane S, Kok M, Ormel H, et al. Limits and opportunities to community health worker empowerment: a multi-country comparative study. Soc Sci Med. 2016;164:27-34.
28 Peters MDJ, Godfrey CM, Khalil H, McInerney P, Parker D, Soares CB. Guidance for conducting systematic scoping reviews. Int J Evid Base Healthc. 2015;13:141-146.

29 Aromataris E, Fernandez R, Godfrey C, Holly C, Kahlil HTP. Checklist for Systematic Reviews and Research Syntheses. Joanna Briggs Inst [Internet]; 2017. Available from: http://joannabriggs.org/research/critical-appraisal-tools.htmlwww.joannabriggs. org\%0Awww.joannabriggs.org.

30 Oikarainen A, Mikkonen K, Kenny A, Tomietto M, Tuomikoski A, Meriläinen M. Educational interventions designed to develop nurses ' cultural competence : a systematic review. Int J Nurs Stud. 2019;98:75-86.

31 Dyrbye L, Shanafelt T. A narrative review on burnout experienced by medical students and residents. Med Educ. 2016;50:132-149.

32 U.S. National Library of Medicine. Fact Sheet: Medical Subject Headings [Internet]. Office of Communications and Public Liaison; 2015. Available from: https://www. nlm.nih.gov/pubs/factsheets/mesh.html.

33 Critical Appraisal Skills Programme. CASP Qualitative Checklist. Casp [Internet]. 2018:1. Available from: http://www.casp-uk.net/casp-tools-checklists.

34 Singh J. Critical appraisal skills programme. J Pharmacol Pharmacother. 2013;4: 76-77.

35 Kangovi S, Mitra N, Grande D, et al. Patient-centered community health worker intervention to improve posthospital outcomes: a randomized clinical trial. J Am Med Assoc Intern Med. 2014;174:535-543.

36 Carod-Artal FJ. Social determinants of mental health. Global Mental Health: Prevention and Promotion. 2017:33-46.

37 Pumariega AJ, Rothe E, Pumariega JAB. Mental health of immigrants and refugees 41. Community Mental Health Journal; 2005:581-597.

38 World Health Organization. Mental Health Gap Action Programme - Scaling up Care for Mental, Neurological, and Substance Use Disorders. World Health Organization; 2008.

39 Ernawati E, Nursalam N, Devy SR. The role of HIV/AIDS cadre on improving quality of life among women with HIV/AIDS in a community setting: a qualitative study. Int J Psychosoc Rehabil. 2020;24:870-879.

40 Sari YIP, Sukartini T, Yunitasari E. Prevention of depression in patients with cancer: a systematic review. Int J Psychosoc Rehabil. 2020;24:7679-7686.

41 Windarwati, Dwi Heni, , Niken Asih Laras Ati, Mareta Deka Paraswati S. Stressor, coping mechanism, and motivation among health care workers in dealing with stress due to the COVID-19 pandemic in Indonesia. Asian J Psychiatr. 2020.

42 Windarwati HD, Oktaviana W, Mukarromah I, Ati NAL, Rizzal AF, Sulaksono AD. In the middle of the COVID-19 outbreak: early practical guidelines for psychosocial aspects of COVID-19 in East Java, Indonesia. Psychiatry Res [Internet. 2020;293, 113395. https://doi.org/10.1016/j.psychres.2020.113395. Available from:.

43 Priestley J, McPherson S. Experiences of adults providing care to a partner or relative with depression: a meta-ethnographic synthesis. J Affect Disord. 2016;192:41-49.

44 Ristkari T, Mishina K, Lehtola MM, Sourander A, Kurki M. Public health nurses' experiences of assessing disruptive behaviour in children and supporting the use of an Internet-based parent training programme. Scand J Caring Sci. 2020;34:420-427.

45 Lannin DG, Vogel DL, Brenner RE, Abraham WT, Heath PJ. Does self-stigma reduce the probability of seeking mental health information? J Counsel Psychol. 2016;63: 351-358.

46 Beiter R, Nash R, McCrady M, et al. The prevalence and correlates of depression, anxiety, and stress in a sample of college students. J Affect Disord. 2015;173:90-96.

47 Prince JP. University student counseling and mental health in the United States: trends and challenges. Ment Heal Prev. 2015;3:5-10.

48 Sharifi V, Tehranidoost M, Yunesian M, Amini H, Mohammadi M, Jalali Roudsari M. Effectiveness of a low-intensity home-based aftercare for patients with severe mental disorders: a 12-month randomized controlled study. Community Ment Health J; 2012. 